\title{
Isolation and Characterization of Enterotoxigenic Coagulase-Positive and Methicillin-Resistant Staphylococcus aureus Contaminating Beef Burger and Hot Dog Sandwiches Retailed in Mansoura City
}

\author{
Eman Abdelkhalik Mohammed ${ }^{1}$, Hazem Ramadan², Samir Mohammed Abd-Elghany ${ }^{1}$, Mahmoud Ahmed Mahros ${ }^{1 *}$
}

${ }^{1}$ Food Hygiene and Control Department, Faculty of Veterinary Medicine, Mansoura University.

${ }^{2}$ Hygiene and Zoonoses Department, Faculty of Veterinary Medicine, Mansoura University.

\section{ARTICLE HISTORY}

Received: 26.07 .2020

Revised: 16.08 .2020

Accepted: 17.08 .2020

Address correspondence to Mahmoud Ahmed Mahros; Tel. +201033016603, Email: mahmoudmahros@yahoo.com), Orcid: 0000-0003-3423-0085

\section{ABSTRACT}

\begin{abstract}
Objective: The study was designed to assess, isolate and characterize coagulase-positive S. aureus and its enterotoxins, in addition to their methicillin resistance contaminating the beef burger and hot dog sandwiches purchased from different fast-food restaurants distributed in Mansoura city.

Design: Observational study.

Procedures: A total of 100 meat (50 beef burger and 50 hot dog) sandwiches were bacteriologically and molecularly analyzed to isolate and characterize the contaminating coagulase-positive S. aureus and its enterotoxins, in addition to their methicillin resistance.

Results: S. aureus was found in $86 \%$ of overall tested samples, $90 \%$ in beef burger and $82 \%$ in hot dog sandwiches, in counts of $5.3 \times 10-2.9 \times 10^{4}, 9.5 \times 10-1.9 \times 10^{4}$ and $1 \times 10-3.8 \times 10^{4}$ and mean counts of $3.9 \times 10^{3}$, $3.5 \times 10^{3}$ and $4.2 \times 10^{3}$, respectively. Of the 106 confirmed coagulase-positive strains, $14(13.2 \%)$ were enterotoxin producing strains and 47 (44.3\%) of them carry the mecA gene confirmed their methicillin resistance. Regarding the microbiological quality of samples according to detected counts, $10 \%, 79 \%$ and $11 \%$ were acceptable, unsatisfactory, and potentially hazardous ready-to-eat meat sandwiches, respectively.

Conclusion and clinical relevance: The results indicated that tested ready-to-eat meat sandwiches were contaminated with enterotoxigenic and methicillin resistant $S$. aureus and represent a potential hazard to consumers; hence strict hygienic measures at fast-food restaurants are crucial.
\end{abstract}

\section{INTRODUCTION}

Staphylococcus aureus (S. aureus), a ubiquitous facultative anaerobic Gram-positive coccus occurs singly, in pairs and irregular clusters, is one of the leading pathogens that causes food poisoning outbreaks, globally [1]. The organism is a commensal and opportunistic pathogen causing infections range from minor skin disorders as wound infections, locally invasive diseases as osteomyelitis, cellulitis, sinusitis, and pneumonia, to life-threatening meningitis and septicemia [2, 3].

Staphylococcus aureus is found on the skin and mucous membranes of humans and warm-blooded animals. It is also isolated from some food products such as meat and meat products which considered an important reservoir for this organism and subsequently involved in numerous outbreaks [4 - 6]. In processed meats, the contamination with $S$. aureus may be resulted from workers with hand or arm lesions or by coughing. The growth and proliferation of $S$. aureus in foods represent a potential health hazard to the consumers, as many strains produce enterotoxins. Therefore, when large numbers of $S$. aureus organisms encountered in processed meat, it may be due to inadequate sanitation, temperature control or both [7].

Staphylococcus aureus can cause food poisoning by producing staphylococcal enterotoxins (SEs) manifested by vomiting, without or with diarrhea, abdominal cramping, and nausea, with symptoms start from half an hour to eight hours after consumption of contaminated foods [8]. SEs are heat resistant and can pass through gastrointestinal tract with no loss of their biological activity because proteolytic enzymes as renin, pepsin and trypsin do not have any effect on SEs [9, 10]. The amount of toxins required to produce food poisoning symptoms ranges from twenty Nano grams to one $\mu \mathrm{g}$ corresponding to $10^{5}$ staphylococci CFU/g of the food [11].

Recently, methicillin resistant $S$. aureus (MRSA) is a pathogen of increasing importance because it usually exhibited multiple antimicrobial resistance and considered by the WHO in 2017 as one of the 12 bacterial families that pose the utmost threat to human health [12]. The organism can be resistant to numerous antimicrobials and quickly disseminates worldwide. In recent years, MRSA caused about 5400 extra deaths [13]. Several foods reported as reservoirs for MRSA strains because 
the organisms have been reported from different foods as beef, poultry, milk, and vegetables [14, 15]. Staphylococcus aureus became MRSA because of the acquisition of the mecA or mecC gene on the staphylococcal cassette chromosome mec ( $\mathrm{SCCmec}$ ), encodes reduced affinity penicillin-binding protein 2a (PBP2a) allows for cell wall biosynthesis at lethal $\beta$-lactam concentrations $[16,17]$.

The widespread distribution of fast-food restaurants and cafeterias which mostly do not meet the required hygienic measures especially those related to food workers, and due to the increase in hours spent outside homes which enforced large numbers of people to consume meat sandwiches from these places, in addition to the increased health risk and multidrug resistance of MRSA. Therefore, the present study was designed to investigate the prevalence of coagulase-positive, enterotoxigenic, and methicillin resistant $S$. aureus contaminating beef burger and hot dog sandwiches retailed in fast-food restaurants and cafeterias distributed at Mansoura city.

\section{MATERIALS AND METHODS}

\subsection{Collection of samples}

A total of 100 meat (50 beef burger and 50 hot dog) sandwiches were purchased from different fast-food restaurants and cafeterias distributed in Mansoura city. Each sample was represented by a sandwich packed individually in a previously marked, clean polyethylene bag, then transferred with a minimum of delay -in icebox- to the laboratory of Meat Hygiene, Food Hygiene and Control Department, Faculty of Veterinary Medicine, Mansoura University, wherein the bacteriological analyses were completed.

\subsection{Isolation and identification of S. aureus [18]}

Ten grams of the meat part of each sample (beef burger or hot dog sandwich) were excised using a sterile scalpel then homogenized for one min, in a laboratory blender (Moulinex, France), with $90 \mathrm{ml}$ of $0.1 \%$ sterile peptone water (Oxoid CM0009) for attaining the original dilution, from which, $1 \mathrm{ml}$ was transferred to sterile test tubes containing $9 \mathrm{ml}$ of the same diluent to prepare serial dilutions (up to $10^{-4}$ ). $0.2 \mathrm{ml}$ of selected dilutions were transferred and evenly spread onto dried surfaces of duplicate plates of Baird-Parker selective agar (Oxoid CM0275) supplemented with egg-yolk tellurite emulsion. The plates allowed to dry then incubated for 48 hours at $37^{\circ} \mathrm{C}$. Characteristic colonies exhibiting typical morphology, grey black to jet-black, shiny, circular, smooth, convex, 2-3 mm in diameter with a narrow white entire margin and may show opaque zones surrounded by zone of clearing extended 2-5 $\mathrm{mm}$ in the opaque medium, were considered a presumptive $S$. aureus. The colonies were counted as an initial count of $S$. aureus until confirmation. The top part of five suspected colonies was inoculated into test tubes containing $5 \mathrm{ml}$ of sterile brain heart infusion broth (Oxoid CM0225) then incubated at $37^{\circ} \mathrm{C}$ for up to 24 hours for confirmation $[19,20]$ : through Gram staining (Gram positive cocci arranged in characteristic irregular clusters resembling bunches of grapes), catalase activity (positive) and salt tolerance (growth on mannitol salt agar). Coagulase test (tube method) was performed to the confirmed strains as follow: From the previously inoculated brain heart infusion (BHI) broth, $0.1 \mathrm{ml}$ was transferred to tubes contain 0.3 $\mathrm{ml}$ of reconstituted rabbit plasma then incubated the for 24 hours at $37{ }^{\circ} \mathrm{C}$. Tubes were observed after $3 \mathrm{~h}$ for fibrin clot formation (coagulase positive). Tubes which did not show clot formation had further incubation for 20 hours and then marked as coagulase negative or positive. S. aureus produces a clot, gelling either the whole contents of the tube or forming a loose web of fibrin. Finally, the total $S$. aureus count per gram of each examined sample was then calculated and recorded.

\subsection{Detection and typing of enterotoxin [21]}

The clear culture supernatant fluid, obtained from individual isolates, was tested serologically by Reverse Passive Latex Agglutination technique "RPLA" using kits for the detection of SEs A, B, C and D (SET-RPLA, Denka Sekeu Ltd, Japan). The sensitivity of this test kit in detection of enterotoxins is $0.5 \mathrm{ng} / \mathrm{ml}$ of test extract. The test was performed in microtiter plate (v-type) arranged so that each row consists of 8 wells and each test sample needed the use of 5 rows of wells. Using a pipette, $25 \mu$ l of diluent were placed in each well then, the sample was picked up simultaneously with 5 diluents ( $25 \mu \mathrm{l}$ each) and two-fold diluents of the test sample were carried out along each of the 5 rows except the last well of each row contained $25 \mu \mathrm{l}$ of diluent only. $25 \mu \mathrm{l}$ quantities of latex suspensions sensitized separately with anti-enterotoxin $A$, $B, C$, and $D$ were added to the wells of each of $1^{\text {st }}, 2^{\text {nd }}, 3^{\text {rd }}$, and $4^{\text {th }}$ row of the plate, respectively while $25 \mu$ l of control latex were added to each well in the fifth row of the plate using, then mixing the contents. The plate was covered and left undisturbed at room temperature for $24 \mathrm{hrs}$. Each well in each row was examined for agglutination.

\subsection{Molecular characterization of isolated S. aureus \\ 2.4.1. Genomic DNA Extraction}

DNA from individual colonies of presumptive $S$. aureus, after overnight culture on $\mathrm{BHI}$ agar plates, was obtained using QIA amp mini kit (Qiagen, Germany, $\mathrm{GmbH}$ ), according to the manufacturers' instructions. The supernatant containing the genomic DNA was transferred to sterile tube and stored at -20 ${ }^{\circ} \mathrm{C}$ until used for PCR.

\subsubsection{DNA Amplification of S. aureus virulence genes [22]}

A multiplex PCR for identification of the thermonuclease (nuc) and methicillin resistance (mecA) virulence genes was performed essentially by using specific primers (Pharmacia Biotech) (Table 1). 
DNA amplification was performed, in a Thermal Cycler (Master cycler, Eppendorf, Hamburg, Germany), in a $50 \mu \mathrm{l}$ reaction volume consisted of $2 \mu \mathrm{DNA}$ template; $0.6 \mu \mathrm{M}$ of each forward and reverse primers; $1 \mathrm{U}$ of Taq DNA polymerase; 2 $\mathrm{mM} \mathrm{MgCl} 2$; dATP, dCTP, dGTP, and dTTP at $200 \mu \mathrm{M}$ each; and $1 x$ PCR buffer ( $\mathrm{pH}$ 8.0). The reaction mixture was overlaid with $30 \mu$ of light mineral oil and heated to $94^{\circ} \mathrm{C}$ for 4 minutes. Parameters for amplification are $30 \mathrm{sec}$ at $94^{\circ} \mathrm{C}$ (denaturation), $30 \mathrm{sec}$ at $55^{\circ} \mathrm{C}$ (annealing), and $1 \mathrm{~min}$ at $72^{\circ} \mathrm{C}$ (extension). Subsequently, primers nuc $1(0.2 \mu \mathrm{M}$ each) were added to the reaction mixture and PCR was continued for 20 cycles, then multiplex PCR were completed with a final extension at $72^{\circ} \mathrm{C}$ for $5 \mathrm{~min}$.

The amplified DNA fragments were analyzed in $1 x$ TBE buffer stained with ethidium bromide by $1.5 \%$ of agarose gel electrophoresis (Applichem, Germany, GmbH) then visualized on UV transilluminator. A 100 bp DNA Ladder (Qiagen, Germany, $\mathrm{GmbH}$ ) was used as a marker to define fragment sizes.

\subsection{Statistical analysis}

The achieved data were processed statistically and presented as mean \pm standard error, using SPSS [25].

\section{RESULTS}

Table 1: Primers used for detection of virulence genes of isolated S. aureus.

\begin{tabular}{|c|c|c|c|}
\hline $\begin{array}{l}\text { Target } \\
\text { Gene }\end{array}$ & Oligonucleotide sequence $\left(5^{\prime} \rightarrow 3^{\prime}\right)$ & $\begin{array}{l}\text { Amplicon } \\
\text { size (bp) }\end{array}$ & Reference \\
\hline Nuc & $\begin{array}{l}\text { F: 5' GCGATTGATGGTGATACGGTT 3' } \\
\text { R: 5' AGCCAAGCCTTGACGAACTAAAGC } 3^{\prime}\end{array}$ & 270 & [23] \\
\hline mecA & $\begin{array}{l}\text { F: 5' TAGAAATGACTGAACGTCCG '3 } \\
\text { R: } 5 \text { ' TTGCGATCAATGTTACCGTAG '3 }\end{array}$ & 533 & [24] \\
\hline
\end{tabular}

F: forward primer; R: reverse primer; bp: base pair.

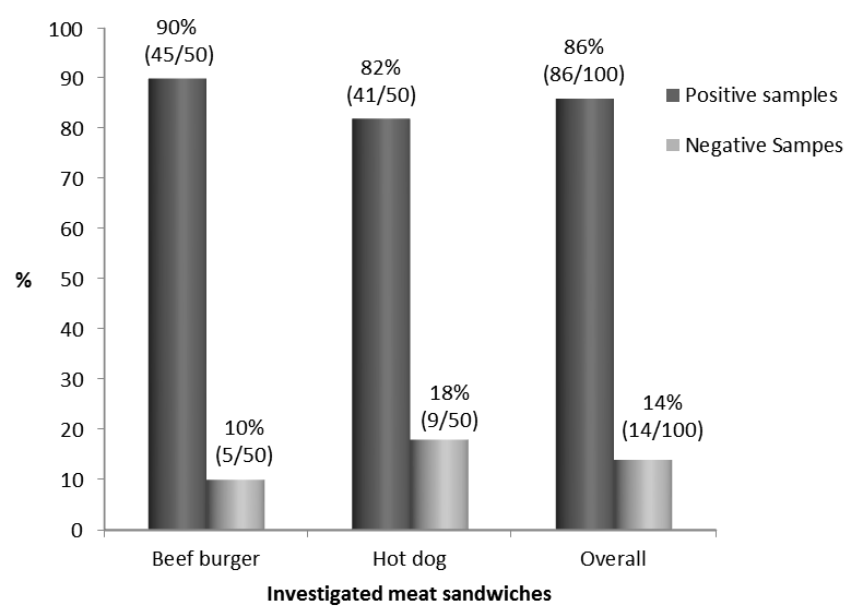

Figure 1: Incidence of S. aureus contamination in investigated sandwiches.
Table 2. Detected counts of $S$. aureus in investigated sandwiches.

\begin{tabular}{llll}
\hline Meat product & Minimum & Maximum & Mean \pm SE* \\
\hline Beef burger & $9.5 \times 10$ & $1.9 \times 10^{4}$ & $3.5 \times 10^{3} \pm 5.4 \times 10^{2}$ \\
\hline Hot dog & $1 \times 10$ & $3.8 \times 10^{4}$ & $4.2 \times 10^{3} \pm 8.9 \times 10^{2}$ \\
\hline Total & $5.3 \times 10$ & $2.9 \times 10^{4}$ & $3.9 \times 10^{3} \pm 5.2 \times 10^{2}$ \\
\hline *Standard Error & & &
\end{tabular}

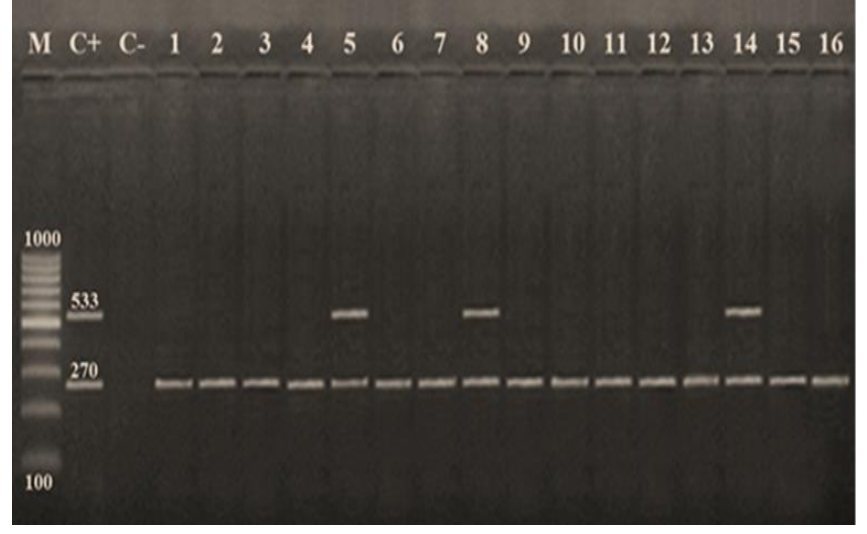

Figure 3. Agarose gel electrophoresis for multiplex PCR products of thermonuclease (nuc) (270 bp) and methicillin (mecA) (533 bp) virulence genes of isolated S. aureus. Lane M: A 100 bp DNA ladder marker; Lane C+: Control positive $S$. aureus strain for nuc and mecA genes; Lane C-: Control negative; Lanes from 1 to 16: Positive $S$. aureus strains for nuc gene; Lanes 5, 8 \& 16: Positive $S$. aureus strains for both nuc and mecA genes.

\section{DISCUSSION}

A total of 100 meat (50 each of beef burger and hot dog) sandwiches were investigated to isolate the coagulase-positive $S$. aureus. Presumptive colonies of $S$. aureus were confirmed by coagulase test and by detecting the thermonuclease (nuc) gene in all confirmed isolates, and the counts were finally calculated. Coagulase-positive $S$. aureus organisms were detected in 86 (86\%), 45 (90\%), and 41 (82\%) of overall, beef burger, and hot dog sandwiches, respectively (Figure, 1 \& 3). The coagulasepositive counts (minimum, maximum and mean) were $5.3 \times 10$, $2.9 \times 10^{4}$ and $3.9 \times 10^{3} ; 9.5 \times 10,1.9 \times 10^{4}$ and $3.5 \times 10^{3}$; and $1 \times 10$, $3.8 \times 10^{4}$ and $4.2 \times 10^{3}$ in overall, beef burger and hot dog sandwiches, respectively (Table, 2 ). Nearly Similar results were reported by [26, 27]. CDC [28] stated the food is contaminated with staphylococci by contact with food handlers who carry it and foods that need no cooking as hamburger sandwiches are susceptible to contaminate with $S$. aureus and subsequent toxin production. 
Table 3: Incidence of $\operatorname{mec} A$ and enterotoxin production among isolated S. aureus $(\mathrm{n}=106)$.

\begin{tabular}{|c|c|c|c|c|c|c|c|c|c|c|c|c|c|c|c|c|c|}
\hline \multirow{3}{*}{$\begin{array}{l}\text { Meat } \\
\text { Sandwich } \\
\text { es }\end{array}$} & \multirow{3}{*}{$\begin{array}{l}\text { No. of isolated } \\
\text { strains }\end{array}$} & \multirow{2}{*}{\multicolumn{2}{|c|}{$\begin{array}{l}\text { No. } \& \% \text { of } \\
\text { mecA- } \\
\text { positive } \\
\text { Strains }\end{array}$}} & \multirow{2}{*}{\multicolumn{2}{|c|}{$\begin{array}{l}\text { No. \& \% of } \\
\text { enterotoxin- } \\
\text { producing } \\
\text { strains }\end{array}$}} & \multicolumn{12}{|c|}{ Enterotoxin production } \\
\hline & & & & & & \multicolumn{2}{|l|}{ A } & \multicolumn{2}{|l|}{ B } & \multicolumn{2}{|l|}{ C } & \multicolumn{2}{|l|}{ D } & \multicolumn{2}{|c|}{$A \& C$} & \multicolumn{2}{|c|}{ A \& D } \\
\hline & & No. & $\%$ & No. & $\%$ & No. & $\%$ & No. & $\%$ & No. & $\%$ & No. & $\%$ & No. & $\%$ & No. & $\%$ \\
\hline $\begin{array}{l}\text { Beef } \\
\text { burger }\end{array}$ & 78 & 36 & 46.2 & 10 & 12.8 & 4 & 5.1 & 2 & 2.7 & - & - & 2 & & - & - & 2 & 2.7 \\
\hline Hot dog & 28 & 11 & 39.3 & 4 & 14.3 & - & - & - & - & 2 & 7.1 & - & - & 2 & 7.1 & - & - \\
\hline Overall & 106 & 47 & 44.3 & 14 & 13.2 & 4 & 3.8 & 2 & 1.9 & 2 & 1.9 & 2 & 1.9 & 2 & 1.9 & 2 & 1.9 \\
\hline
\end{tabular}

Regarding the microbiological quality of tested samples as ready-to-eat meat, $10 \%(10 / 100), 12 \%(6 / 50)$, and $8 \%(4 / 50)$; $79 \%(79 / 100), 78 \%(39 / 50)$, and $80 \%(40 / 50)$; and $11 \%$ $(11 / 100), 10 \%(5 / 50)$, and $12 \%(6 / 50)$ of overall, beef burger, and hot dog sandwiches investigated were acceptable (low risk), unsatisfactory (moderate risk) and potentially hazardous (high risk), respectively [29]. These results mean that most (79\%) of tested sandwiches contaminated with higher counts of S. aureus organisms which represent a moderate risk to consumers and $11 \%$ of them are potentially injurious to health and/or unfit for human consumption (Figure, 2).

The results showed a higher (86\%) contamination level of tested sandwiches and higher detecting counts (mean of $2.9 \times 10^{4}$ ), besides $11 \%$ of samples exceeding the limits recommended by Health Protection Agency [29] for ready-toeat meats indicating poor hygienic measures during preparing, cooking and handling of these sandwiches in restaurants and subsequent potential risk because sandwiches contaminated with SEs may not smell bad or look spoiled and these organisms can multiply in the food and produce enterotoxins that can make people ill. However, $S$. aureus bacteria are killed by cooking; their toxins are not destroyed and will still be able to cause illness [9]. It is established that meat products should be free from $S$. aureus enterotoxins according to Egyptian Organization for Standardization [30].

Out of 106 isolates of confirmed coagulase-positive $S$. aureus from all meat sandwiches tested, the gene encoding the methicillin resistance $(\operatorname{mec} A)$ was detected in $47(44.3 \%)$ while only 14 (13.2) were enterotoxin producing (Figure, 3 \& Table, 3). The four enterotoxins detected were SE A (3.8\%), and SE B, SE C, SE D, SE A \& C, and SE A \& D (1.9\%, each). The mecA gene could be detected in $25 \%$ of tested $S$. aureus isolates [27]. On the other hand, SE A and SE D could be detected in 3.6\% (each) of $S$. aureus contaminating examined street vendor meat samples [31]. Similar results were also detected [26]. 15-80\% of isolated $S$. aureus are enterotoxigenic and ready-to-eat meat products are contaminated during mixing and handling the ingredients [32]. Generally, MRSA and its enterotoxins when found indicate lack of hygiene during food production [33], and the overuse of antibiotics in animals and humans lead to increasing the presence of these strains [34].

\section{Conclusion}

It can be concluded that investigated beef burger and hot dog sandwiches retailed in Mansoura city showed higher degree of contamination with coagulase-positive, enterotoxin producing and methicillin resistant $S$. aureus organisms. Hence, consumption of such sandwiches may constitute potential health risk. Therefore, strict control measures should be followed to ensure the safety of these meat sandwiches to consumers.

\section{Conflict of interest statement}

No conflict of interest.

\section{Research Ethics Committee permission}

The research was conducted according to standards of Research Ethics Committee, Faculty of Veterinary Medicine, Mansoura University.

\section{Authors' contribution}

Mohammed E. A. collected the samples carried out the practical part. Ramadan $\mathrm{H}$. is a co-supervisor. Abd-Elghany S. M. designed the experiment, supervised the practical work, and revised the manuscript. Mahros $\mathrm{M}$. A. supervised the practical part, drafted, and revised the manuscript.

\section{REFERENCES}

[1] Atanassova V, Meindl A, Ring C. Prevalence of S. aureus and staphylococcal enterotoxins in raw pork and uncooked smoked ham- a comparison of classical culturing detection and RFLP-PCR. Int J Food Microbiol 2001;68: 105-13. https://doi.org/10.1016/S0168-1605(01)00479-2

[2] Popovich KJ, Hota B. Treatment and prevention of community associated methicillin-resistant Staphylococcus aureus skin and soft tissue infections. Dermato Therapy 2008;21:167-79. https://doi.org/10.1111/j.15298019.2008.00188.x

[3] David MZ, Daum RS. Community-associated methicillin-resistant Staphylococcus aureus: epidemiology and clinical consequences of an emerging epidemic. Clin Microbiol Rev 2010;23:616-87. https://doi.org/10.1128/CMR.00081-09 
[4] Irlinger F. Safety assessment of dairy microorganisms: coagulase-negative staphylococci. Int J Food Microbiol 2008;126(3):302-10. https://doi.org/10.1016/j.ijfoodmicro.2007.08.016

[5] Wang X, Tao X, Xia X, Yang B, Xi M, Meng J, Zhang J, Xu B. Staphylococcus aureus and methicillin-resistant Staphylococcus aureus in retail raw chicken in China. Food Control 2013;29:103-6. https://doi.org/10.1016/j.foodcont.2012.06.002

[6] Sallam KI, Abd-Elghany SM, Elhadidy M, Tamura T. Molecular characterization and antimicrobial resistance profile of methicillinresistant Staphylococcus aureus in retail chicken. J Food Protec 2015;78:1879-84. https://doi.org/10.4315/0362-028X.JFP-15-150

[7] Bennett RW, Hait JM, Tallent SM. Staphylococcus aureus. In: Labbé RG, García S (Eds.), Guide to Foodborne Pathogens, $2^{\text {nd }}$ ed., John Wiley \& Sons, Ltd., 2013. https://doi.org/10.1002/9781118684856.ch2

[8] Le Loir Y, Baron F, Gautier M. S. aureus and food poisoning. Genet Molecu Res 2003;2(1):63-76.

[9] Bergdoll MS, Crass B, Reiser R, Robbins R, Davis J. A new staphylococcal enterotoxin, enterotoxin $F$, associated with toxic-shock syndrome Staphylococcus aureus isolates. Lancet 1981;317:1017-21. https://doi.org/10.1016/S0140-6736(81)92186-3

[10] Huy YH. Foodborne disease handbook: diseases caused by bacteria. Marcel Dekker, New York, 1994.

[11] Normanno G, La Salandra G, Dambrosio A, Quaglia N, Corrente M, Parisi A, Santagada G, Firinu A, Crisetti E, Celano G. Occurrence, characterization and antimicrobial resistance of enterotoxigenic $S$. aureus isolated from meat and dairy products. Int J Food Microbiol 2007;115:290-96. https://doi.org/10.1016/j.ijfoodmicro.2006.10.049

[12] Govindaraj AV, Vanitha A. WHO global priority pathogens list on antibiotic resistance: an urgent need for action to integrate one health data. Perspectives in Public Health 2018;138:87-8. https://doi.org/10.1177/1757913917743881

[13] Kobayashi SD, Malachowa N, Deleo FR. Pathogenesis of Staphylococcus aureus abscesses. Amer J Pathol 2015;185:1518-27. https://doi.org/10.1016/j.ajpath.2014.11.030

[14] Wang X, Li, G, Xia X, Yang B, Xi M, Meng J. Antimicrobial susceptibility and molecular typing of methicillin-resistant Staphylococcus aureus in retail foods in Shaanxi, China. Foodborne Pathog Dis 2014;11:281-86. https://doi.org/10.1089/fpd.2013.1643

[15] Wu S, Huang J, Wu Q, Zhang F, Zhang J, Lei T, Chen M, Ding Y, Xue L. Prevalence and characterization of Staphylococcus aureus isolated from retail vegetables in China. Frontiers Microbiol 2018;9:1263. https://doi.org/10.3389/fmicb.2018.01263

[16] Banerjee R, Gretes M, Li B, Strynadka N, Chambers FH. In vitro selection and characterization of ceftobiprole-resistant methicillin resistant Staphylococcus aureus. Antimicrob Agents Chemother 2008;52:2089-96. https://doi.org/10.1128/AAC.01403-07

[17] Garcíaálvarez L, Holden MT, Lindsay H, Webb CR, Brown DF, Curran MD et al. Methicillin-resistant Staphylococcus aureus with a novel mecA homologue in human and bovine populations in the UK and Denmark: a descriptive study. Lancet Infect Dis 2011;11:595-603. https://doi.org/10.1016/S1473-3099(11)70126-8

[18] ISO. ISO 6888-1:1999/AMD 2:2018. Microbiology of Food and Animal Feeding Stuffs - Horizontal method for the enumeration of coagulasepositive staphylococci (Staphylococcus aureus and other Species) - Part 1: Technique using Baird-Parker agar medium - Amendment 2: Inclusion of an alternative confirmation test using RPFA stab method. ISO, (2018): Geneva, Switzerland.

[19] Cruickshank R, Duguid J, Marmion B, Swain RH. Medical Microbiology. $12^{\text {th }}$ ed., Edinburg, London and New York, 1975.

[20] MacFaddin JF. Biochemical tests for identification medical bacteria. Warery Press Inc, Baltimore, Md. 21202 USA, 2000.

[21] Shingaki M, Igarashi $H$, Fujikawa $H$, Ushioda $H$, Terayrna T, Sakai S. Study on Reversed Passive Latex Agglutination for detection of staphylococcal enterotoxins A, B, and C. Annual report of the Tokyo Metropolitan Research Laboratory of Public Health 1981;32(1):128-31.
[22] Shah D, Shringi S, Besser T, Call D. Molecular detection of foodborne pathogens, In Liu, D. (Ed), pp. 369-89. Boca Raton: CRC Press, Taylor \& Francis group, Florida, USA, 2009.

[23] Brakstad OG, Aasbakk K, Maeland JA. Detection of Staphylococcus aureus by polymerase chain reaction amplification of the nuc gene. J Clin Microbiol 1992;30:1654-60. https://doi.org/10.1128/JCM.30.7.16541660.1992

[24] Jukes L, Mikhail J, Bome-Mannathoko N, Hadfield SJ, Harris LG, El-Bouri K, Davies AP, Mack D. Rapid differentiation of Staphylococcus aureus, Staphylococcus epidermidis and other coagulase-negative staphylococci and methicillin susceptibility testing directly from growth-positive blood cultures by multiplex real-time PCR. J Med Microbiol 2010;59:1456-61. https://doi.org/10.1099/jmm.0.023168-0

[25] SPSS "Statistical Package for the Social Sciences". SPSS/PC+ (2004), for the PC/XT. SPSS INC, 2004.

[26] Ali SFH, Abdel Aziz DA. Incidence of enterotoxigenic Staphylococcus aureus in some ready-to-eat meat in Assiut city with special reference to methicillin resistant Staphylococcus aureus strains. Assiut Vet Med J 2015;7(129):95-106.

[27] Saad MS, Hassanin FS, Shaltout FA, Nassif MZ, Seif MZ. Prevalence of methicillin-resistant Staphylococcus aureus in some ready-to-eat meat products. Amer J Biomed Sci Res 2019;4:461-65. https://doi.org/10.34297/AJBSR.2019.04.000855

[28] CDC (Centers for disease control and prevention). Staphylococcal Food Poisoning, 2018. https://www.cdc.gov/foodsafety/diseases/staphylococcal.html

[29] Health Protection Agency. Microbiological Safety of Ready-to-Eat Foods. London: Health Protection Agency, 2009.

[30] Egyptian Organization for Specification and Quality Control (EOS). Physical and chemical methods for examination of fish and fish products salted fish. Egyptian Organization for Standardization and Quality Control No. (1) $-1725 / 2005$.

[31] Hassan MA, Nassif MZ, Ibrahim MA. Incidence of Staphylococcus aureus in meat products with special reference to enterotoxins. Benha Vet Med J 2016;30:23-7. https://doi.org/10.21608/bvmj.2016.31323

[32] Bania J, Dabrowska A, Korzekwa K, Zarczynska A, Bystron J, Chrzanowska J, Molenda J. The profiles of enterotoxin genes in $S$. aureus from nasal carriers. Letters Appl Microbiol 2006;42:315-20. https://doi.org/10.1111/j.1472-765X.2006.01862.x

[33] Alarcon B, Vicedo B, Aznar R. PCR-based procedures for detection and quantification of Staphylococcus aureus and their application in food. J Appl Microbiol 2006;100:352-64. https://doi.org/10.1111/j.13652672.2005.02768.x

[34] Chambers HF. Methicillin resistance in staphylococci: molecular and biochemical basis and clinical implications. Clin Microbiol Rev 1997;10:781-91. 